\title{
AVALIAÇÃO DO IMPACTO DE SUCESSIVOS CHOQUES OSMÓTICOS SOBRE A VIABILIDADE DE CÉLULAS DE LEVEDURA Saccharomyces cerevisiae
}

\author{
F. G. M de MEDEIROS ${ }^{1}$ e M. R. da S. PEDRINI ${ }^{1}$ \\ ${ }^{1}$ Universidade Federal do Rio Grande do Norte, Departamento de Engenharia Química \\ E-mail para fabio.macedo@live.com
}

\begin{abstract}
RESUMO - A osmoporação é uma técnica de microencapsulação com aplicação na indústria de alimentos baseada em eventos osmorregulatórios presentes em células de microrganismos. A aplicação de tratamento hiperosmótico desidrata a célula que, quando reidratada na presença de solução isotônica, promove um grande trânsito de água no sentido intracelular, em virtude da criação de permeabilidade temporária na membrana, permitindo a internalização moléculas de interesse e transformando as células em microcápsulas pré-formadas com pequena alteração na sua viabilidade. Portanto, o presente trabalho teve como objetivo avaliar a aplicação de choques osmóticos sequenciais em células de $S$. cerevisiae quanto ao impacto sobre a viabilidade celular. Para tanto, o protocolo de tratamento osmótico foi aplicado com soluções aquosas de glicerol (1,4 e 30 $\mathrm{MPa}$ ), com posterior suspensão das células em PBS e cultivo de meio MaltWickerham, a $30{ }^{\circ} \mathrm{C}$ por $48 \mathrm{~h}$. A viabilidade foi expressa em UFC/mL e em porcentagem, quando comparada a células que não sofreram choques osmóticos. Foi observado que, apesar de a ocorrência de um evento osmótico não represente grande queda na viabilidade, reduzida a $78,3 \pm 3,2 \%$, a ocorrência de três choques sucessivos já reduz substancialmente a viabilidade celular, a 15,5 $\pm 1,5 \%$, inviabilizando etapas posteriores.
\end{abstract}

\section{INTRODUÇÃO}

Existem diversas técnicas de microencapsulação descritas na literatura, que levam em consideração uma extensa gama de agentes encapsulantes, bem como as vastas aplicações das microcápsulas. Parâmetros como propriedades físico-químicas das substâncias a encapsular e a serem encapsuladas, a finalidade das microcápsulas e o mecanismo de liberação do agente encapsulado devem ser levados em consideração na escolha do método ideal (Zuidam e Shimoni, 2010). Diversos métodos de microencapsulação têm utilização na indústria de alimentos, por exemplo, spray-drying, liofilização e a microencapsulação em lipossomas (Brasileiro, 2011). Apesar das vantagens atribuídas à microencapsulação de componentes, os custos de implementação e aumento da complexidade do processo são apontados como desvantagens associadas à técnica (Zuidam e Shimoni, 2010).

Fang e Bhandari (2010), entretanto, apontam a utilização de células de levedura como uma alternativa interessante para as técnicas de microencapsulação aplicadas à indústria de alimentos. Métodos como a plasmólise e eletroporação já foram reportados como úteis na 
encapsulação de moléculas bioativas em células de levedura, uma vez que estas apresentam características essenciais de estabilidade e proteção ao conteúdo encapsulado (Dardelle et al., 2007; Paramera et al., 2011; Pham-Hoang et al., 2015). Contudo, a viabilidade das células de levedura após o processo de encapsulação tornou-se fator limitante para a utilização desses métodos, uma vez que é afetada negativamente.

A partir dos estudos de Dupont et al. (2010; 2011), que descreveram a criação de permeabilidade temporária na estrutura da membrana plasmática de células de Saccharomyces cerevisiae como resultado de alterações osmóticas brandas e não-letais no meio extracelular sem impacto significativo na viabilidade destas células, Pedrini et al. (2014) foram capazes de propor um método alternativo de incorporação de moléculas hidrofílicas de alto peso molecular em células de levedura, a osmoporação. Nessa técnica, o tratamento de células de S. cerevisiae com solução de glicerol de baixa atividade de água promove a desidratação da célula e o aparecimento de rugosidades ao longo de toda a extensão da membrana; a etapa posterior é de reidratação com solução isotônica de glicerol acrescida do componente a ser encapsulado - nesse ponto, a membrana plasmática se torna temporariamente permeável e ocorre a penetração do composto de interesse em todo o citoplasma, ao invés de através de simples endocitose.

Estudos posteriores demonstraram ainda que essa técnica não alterava significativamente a viabilidade celular após a encapsulação e que moléculas de característica hidrofóbica e peso molecular relativamente menor também poderiam ser encapsuladas em células de levedura (Câmara Júnior et al., 2014; Câmara Júnior et al., 2016). Câmara Júnior (2014) conduziu um estudo que descreveu a influência das variáveis de processo (concentração do composto a encapsular, temperatura e pressão osmótica de desidratação) sobre a eficiência de encapsulação e determinou as condições ótimas para conduzir a incorporação de moléculas bioativas em células de S. cerevisiae.

Portanto, o presente estudo objetivou avaliar a aplicação sequencial de etapas de osmoporação em células de $S$. cerevisiae quanto ao seu impacto na viabilidade celular.

\section{MATERIAIS E MÉTODOS}

\subsection{Reagente e materiais}

A aplicação dos choques osmóticos é realizada utilizando soluções aquosas de glicerol (Sigma-Aldrich) em concentrações tais a garantir as pressões osmóticas $(\pi)$ necessárias. A desidratação das células foi realizada com solução de pressão osmótica $30 \mathrm{MPa}\left(\mathrm{a}_{\mathrm{w}}=0,8\right)$, enquanto para a reidratação utilizou solução isotônica $\left(a_{w}=0,99\right)$ de pressão osmótica 1,4 MPa.

A pressão osmótica das soluções relaciona-se com a atividade de água $\left(a_{w}\right)$ destas a através da Equação 1 (Dupont et al., 2010).

$$
\pi=\frac{-\operatorname{RTIn}_{w}}{V_{w}}
$$


Onde $\mathrm{R}$ representa a constante universal dos gases $\left(\mathrm{J} \cdot \mathrm{mol}^{-1} \cdot \mathrm{K}^{-1}\right)$, T representa a temperatura $(\mathrm{K})$ e $\mathrm{V}_{\mathrm{w}}$ é o volume parcial molar de água na solução $\left(\mathrm{m}^{3} \cdot \mathrm{mol}^{-1}\right)$.

\subsection{Condições de cultivo}

Cepas de Saccharomyces cerevisiae foram cultivadas adequadamente em placas de Petri contendo meio Malt-Wickerham (MW) modificado (3 g de extrato de levedura; $3 \mathrm{~g}$ de peptona pancreática; $10 \mathrm{~g}$ de glicose; $1,5 \mathrm{~g}$ de fosfato de sódio monobásico anidro; $51 \mathrm{~g}$ de glicerol; $1000 \mathrm{~g}$ de água destilada), solidificado com ágar $\left(15 \mathrm{~g} . \mathrm{L}^{-1}\right)$, a $30{ }^{\circ} \mathrm{C}$ por $48 \mathrm{~h}$ (Câmara Júnior et al., 2016). Três colônias isoladas foram transferidas para $100 \mathrm{~mL}$ do meio MW-modificado e incubadas sob agitação de $250 \mathrm{rpm}$, a $25{ }^{\circ} \mathrm{C}$ por $48 \mathrm{~h}$. Uma alíquota foi então transferida para $100 \mathrm{~mL}$ do meio MW-modificado e cultivada por $24 \mathrm{~h}$ nas mesmas condições de agitação e temperatura, garantindo uma concentração celular na ordem de $2 \mathrm{x}$ $10^{8}$ células. $\mathrm{mL}^{-1}$.

A partir dessa cultura, centrifugou-se $40 \mathrm{~mL}$, por $5 \mathrm{~min}$, a $2200 \mathrm{xg}$ a $25{ }^{\circ} \mathrm{C}$. O precipitado foi, então, lavado duas vezes com solução isotônica de glicerol (1,4 MPa) e ressuspendido em $20 \mathrm{~mL}$ desta solução a fim de se submeter ao processo de choques osmóticos.

\subsection{Aplicação dos tratamentos osmóticos sucessivos}

A partir da suspensão celular em solução isotônica, transferiu-se $1,5 \mathrm{~mL}$ para microtubo do tipo Eppendorf, que foi submetido a centrifugação a $4000 \mathrm{xg}$ durante $10 \mathrm{~min}$. $\mathrm{O}$ precipitado foi submetido a desidratação, mediante adição do mesmo volume de solução hiperosmótica de glicerol (30 MPa). Os microtubos foram incubados sob agitação de $250 \mathrm{rpm}$ por 60 minutos, a $25^{\circ} \mathrm{C}$.

Após esse período, os microtubos foram novamente centrifugados e ao precipitado foi adicionado $1,5 \mathrm{~mL}$ de solução isotônica, a fim de promover a reidratação deste. Os tubos foram vigorosamente agitados por 5 segundos e, em seguida, incubados novamente nas mesmas condições.

Esse processo (desidratação e reidratação) foi repetido até que o grupo de células tenha sido submetido a três eventos osmóticos sequenciais. Uma vez submetidas a cada etapa, amostras das suspensões foram centrifugadas, lavadas duas vezes com solução de tampão fosfato-salino (PBS) e foram obtidas as diluições seriadas adequadas.

\subsection{Avaliação da viabilidade celular}

De cada diluição, foram transferidos $100 \mu \mathrm{L}$, em triplicata, para placas de Petri contendo $20 \mathrm{~mL}$ do meio MW-modificado solidificado, e espalhados com auxílio de alça de Drigalski. As placas foram incubadas por $48 \mathrm{~h}$, a $30{ }^{\circ} \mathrm{C}$, e os resultados foram calculados em UFC/mL. Como padrão de comparação, um grupo de células que não sofreu qualquer choque osmótico foi utilizado como controle. A viabilidade celular foi expressa em porcentagem em relação a este controle.

\subsection{Análise estatística dos resultados}


Os resultados foram estatisticamente tratados através do software STATISTICA ${ }^{\circledR}$ (versão 8.0). Utilizou-se a análise de variância de um fator (one-way ANOVA), estabelecendo o número de tratamentos osmóticos como variável independente. Combinado à ANOVA, foi realizado o Teste de Tukey HSD post hoc para determinar quais conjuntos de dados apresentavam diferença significativa, a $95 \%$ de confiança. A utilização desses dois testes estatísticos tem sido descrita na literatura como de fácil aplicação, além de gozar da robustez e confiabilidade necessárias (Granato et al., 2014).

\section{RESULTADOS E DISCUSSÃO}

Avaliar a viabilidade das células submetidas a sequências de tratamentos osmóticos é de valiosa importância para compreender o processo de osmoporação, visto que determina a possiblidade de posterior aplicação destas células em processos industriais que dependam dessa condição.

Os ensaios de viabilidade foram realizados em triplicata e os resultados médios foram expressos em porcentagem, em comparação ao grupo de células que não foi submetido aos múltiplos choques osmóticos. As Tabelas 1 e 2 apresentam a análise de variância (ANOVA) e os resultados médios de viabilidade celular em função do número de choques osmóticos aplicados na célula.

Tabela 1 - Análise de variância (ANOVA) dos dados de viabilidade celular. $\mathrm{F}_{\text {tabelado(1;22.0,05) }}=$ 4,30

\begin{tabular}{|c|c|c|c|c|}
\hline Variação & $g l$ & SQ & MQ & Fcalc \\
\hline Entre grupos & 1 & 4,4376 & 4,4376 & 6,0369 \\
\hline Dentro dos grupos & 22 & 16,1717 & 0,7351 & \\
\hline
\end{tabular}

Os dados da Tabela 1 indicam que existe diferença significativa $(p<0,05)$ entre os dados de viabilidade quando comparado o número de etapas de choques osmóticos sofridas pelas células, uma vez que o valor de $F_{\text {calculado }}(6,0369)>F_{\text {tabelado }}(4,30)$. Os dados apresentados na Tabela 2 permitem inferir que quanto maior é a sequência de choques hiperosmóticos a qual a célula de levedura é submetida, maior é o impacto na taxa de viabilidade; ou seja, o número de tratamentos osmóticos é inversamente proporcional a viabilidade celular.

Tabela 2 - Dados médios de viabilidade celular em UFC/mL, e em porcentagem em relação ao controle (\%). Média \pm Desvio padrão. Diferenças significativas, expressas por letras distintas na mesma coluna, pelo Teste de Tukey $(p<0,05)$

\begin{tabular}{|c|c|c|}
\hline $\begin{array}{c}\text { Número de tratamentos } \\
\text { osmóticos }\end{array}$ & $\begin{array}{c}\text { Viabilidade celular } \\
\left(10^{6} \mathrm{UFC} / \mathrm{mL}\right)\end{array}$ & Viabilidade celular (\% em relação ao controle) \\
\hline \hline 0 & $3,24 \pm 0,17$ & $100,0 \pm 0,0^{\mathrm{a}}$ \\
\hline \hline 1 & $2,53 \pm 0,14$ & $78,3 \pm 3,2^{\mathrm{b}}$ \\
\hline 2 & $2,00 \pm 0,17$ & $62,1 \pm 8,4^{\mathrm{c}}$ \\
\hline 3 & $0,51 \pm 0,08$ & $15,5 \pm 1,5^{\mathrm{d}}$ \\
\hline
\end{tabular}


Dupont et al. $(2010,2011)$ demonstram que a durante a desidratação de células de levedura por ocasião de mudanças osmóticas no meio, a estrutura da membrana celular é afetada, causando rugosidades e o rearranjo da estrutura lipídica presente nesta, o que altera sua fluidez. Esse fenômeno ocorre em virtude da adaptação osmorregulatória da célula, que promove grande trânsito de água no sentido do extracelular.

Nesse estudo, os autores demonstraram que a intensidade do choque osmótico e o perfil cinético de alteração da pressão osmótica (Figura 1) são duas variáveis que tem influência na viabilidade celular. Ainda nesse estudo, a aplicação de tratamento osmótico com pressão de $30 \mathrm{MPa}$, com perfil que segue uma desidratação rápida, manutenção da pressão por 60 minutos, e reidratação rápida com solução isotônica seguida por manutenção por 60 minutos, resultou em viabilidade na ordem de $83,5 \pm 2,5 \%$, que não difere significativamente $(p>0,05)$ dos resultados encontrados no presente estudo, para o caso da aplicação de um único choque osmótico, seguindo o mesmo perfil cinético de alteração de pressão.

Figura 1 - Perfis cinéticos de alteração de pressão osmótica no meio. (A) Desidratação e reidratação graduais. (B) Desidratação gradual e reidratação rápida. (C) Desidratação rápida e reidratação gradual. (D) Desidratação e reidratação rápidas

Perfis cinéticos de mudança de pressão osmótica no meio

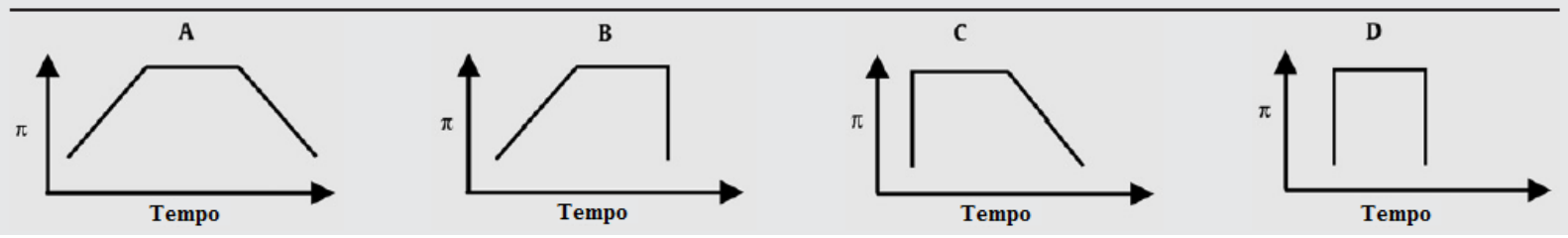

García (2011), em um estudo sobre a sobrevivência de bactérias em meios com reduzida atividade de água, destacou que os protocolos de desidratação das células exercem grande influência na possível viabilidade celular também para estes microrganismos. Mille et al. (2002) também investigaram a influência de choques hiperosmóticos sobre a viabilidade de bactérias e mostram que células de Escherichia coli também são capazes de resistir, com discreta redução na viabilidade, a variações moderadas (26 MPa) na pressão osmótica do meio em que se encontram.

Apesar de a literatura disponível sobre o assunto demonstrar que as células de levedura são capazes de suportar a administração de um evento osmótico, os estudos disponíveis não deixam claro qual o impacto do emprego de eventos sucessivos sobre a viabilidade. A partir dos dados apresentados, fica claro que as desidratações e reidratações sucessivas na mesma célula, embora possam ser associadas ao aumento de eficiência nas etapas do processo de osmoporação, tem grande impacto na viabilidade celular.

Entre as hipóteses que possivelmente explicam esse comportamento, pode-se destacar que a criação de rugas e dobras na membrana plasmática, durante o processo de desidratação, bem como o rearranjo da estrutura fosfolipídica desta, podem não ser completamente revertidos durante a reidratação, afetando a capacidade das células de levedura de se reproduzirem, ou ainda comprometendo estruturas necessárias para a sobrevivência como, por exemplo, as proteínas presentes na membrana. 
Além disso, embora a pressão osmótica aplicada não seja excessiva, células fragilizadas por motivos quaisquer podem ter sua capacidade osmorregulatória comprometida, fazendo com que não sejam capazes de se adequar perfeitamente ao protocolo de choques osmóticos sucessivos. Dessa forma, estudos posteriores seriam necessários para determinar, com precisão, o comportamento da membrana plasmática das células de levedura quando submetidas a eventos sequenciais de desidratação e reidratação rápidas.

\section{CONCLUSÕES}

A técnica de osmoporação é uma alternativa tecnológica interessante com promissoras aplicações não só na indústria de alimentos, uma vez que possibilita a bioencapsulação de moléculas de interesse de maneira simples. Para tanto, conhecer as características e limitações do processo é essencial. Nesse estudo, foram simuladas etapas sequenciais de osmoporação a serem aplicadas em células de $S$. cerevisiae para avaliar o impacto destas na viabilidade celular. Observou-se que, apesar da administração de um tratamento osmótico não implicar em redução acentuada da viabilidade, com taxas na ordem de 78,3 $\pm 3,2 \%$, o alongamento do processo até o terceiro tratamento osmótico já proporciona redução substancial da viabilidade, com taxas na ordem de $15,5 \pm 1,5 \%$. Recomenda-se, portanto, a utilização de, no máximo, dois choques osmóticos, a fim de aumentar a eficiência da técnica de osmoporação sem inviabilizar a utilização das leveduras posterior das leveduras.

\section{REFERÊNCIAS}

BRASILEIRO, J. S. L. Microencapsulação de compostos bioactivos: inovação em diferentes áreas. Universidade Fernando Pessoa. Porto, Portugal, p. 71. 2011.

CÂMARA JÚNIOR, A. D. A. Microencapsulação de Fisetina em Células de Levedura (Saccharomyces cerevisiae) Através de Choque Osmótico. Universidade Federal do Rio Grande do Norte. Natal, RN, p. 87. 2014.

CÂMARA JÚNIOR, A. D. A. et al. Avaliação de efeitos físico-químicos na eficiência da bioencapsulação de flavonoide lipossolúvel em célula de levedura (Saccharomyces cerevisiae) através de choque osmótico. Anais do XX Congresso Brasileiro de Engenharia Química. Florianóplis, SC: [s.n.]. Outubro 2014.

CÂMARA JÚNIOR, A. D. A. et al. Fisetin yeast-based bio-capsules via osmoporation: effects of process variables on the encapsulation efficiency and internalized fisetin content. Applied Microbial and Cell Physiology, 2016.

DARDELLE, G. et al. Flavour-encapsulation and flavour-release performances of a commercial yeast-based delivery system. Food Hydrocolloids, 2007. 953-960.

DUPONT, S. et al. Lateral reorganization of plasma membrane is involved in the yeast resistance to severe dehydration. Biochimica et Biophysica Acta, 2010. 975-985.

DUPONT, S. et al. Nature of sterols affects plasma membrane behavior and yeast survival during dehydration. Biochimica et Biophysica Acta, 2011. 
FANG, Z.; BHANDARI, B. Encapsulation of polyphenols - a review. Trends in Food Science \& Technology, 21, 2010. 510-523.

GARCIA, A. H. Anhydrobiosis in bacteria: From physiology to applications. Journal of Biosciences, 2011. 939-950.

GRANATO, D.; CALADO, V. M. D. A.; JARVIS, B. Observations on the use of statistical methods in Food Science and Technology. Food Research International, 55, 2014. 137 149 .

MILLE, Y.; BENEY, L.; GERVAIS, P. Viability of Escherichia coli after combined osmotic and thermal treatment: a plasma membrane implication. Biochimica et Biophysica Acta, 1567, 2002. 41-48.

PARAMERA, E. I.; KONTELES, S. J.; KARATHANOS, V. T. Stability and release properties of curcumin encapsulated in Saccharomyces cerevisiae, B-cyclodextrin and modified starch. Food Chemistry, 2011. 913-922.

PEDRINI, M. R. D. S. et al. Osmoporation: a simple way to internalize hydrophilic molecules into yeast. Applied Microbial and Cell Physiology, 2014. 1271-1280.

PHAM-HOANG, B.-N.; PHAN-THI, H.; WACHÉ, Y. Can biological structures be natural and sustainable capsules? Frontiers in Chemistry, June 2015. 1-4, 